\title{
ACCIÓN DEL ESTADO Y ACCIÓN COMUNITARIA EN LA GESTIÓN DE LA VIVIENDA POST ERUPCIÓN DEL VOLCÁN CHAITÉN, CHILE: DOS ESTRATEGIAS DIVERGENTES ${ }^{1}$
}

RICARDO TAPIA Z. ${ }^{\text {a }}$

\section{RESUMEN}

Como consecuencia del impacto de la erupción del Volcán Chaitén en el año 2008, más de 4000 familias debieron abandonar sus viviendas y fueron desplazadas a diferentes localidades y ciudades de la Isla de Chiloé y el continente. Al 2015, cerca de un 40\% de los habitantes han retornado a la ciudad la cual fue definida como un área no apta para la vida humana por su predisposición potencial a ser afectada por riesgos provenientes de la naturaleza.

Mediante la revisión de políticas y acciones aplicadas por parte del Estado, procedimientos, análisis en terreno, fuentes secundarias y entrevistas a los afectados, se concluye que la comprensión y dimensión del daño y las estrategias utilizadas, en aspectos alusivos a la vivienda en este desastre socionatural, tienen un efecto sesgado, limitado y por tanto negativo, en la gestión del riesgo, principalmente en la etapa de reconstrucción y reasentamiento de los habitantes damnificados puesto que no lograron articular los intereses y expectativas de la comunidad chaitenina.

Las estrategias aplicadas por parte del Estado para el tratamiento de la gestión de la vivienda en el desastre de Chaitén: ¿fueron las adecuadas? ¿Estuvieron en consonancia con las aspiraciones y expectativas de sus habitantes?

Este proceso, en desarrollo y aun inconcluso, adolece de limitaciones conceptuales en su comprensión, diseño y gestión, teniendo como consecuencias, graves daños en la calidad de vida de los habitantes involucrados. La vivienda, como activo de capital físico no fue considerada en su valor intrínseco, más allá de su condición de bien patrimonial.

PALABRAS CLAVE: vivienda, políticas públicas, Chaitén, gestión del riesgo, erupción volcánica.

1 El presente trabajo es parte del Proyecto de Investigación financiado por iniciativa Milenio NS 100022 del Ministerio de Economía, Fomento y Turismo del Gobierno de Chile.

a Chile, Instituto de la Vivienda. Facultad de Arquitectura y Urbanismo, Universidad de Chile y Núcleo Milenio de Investigación en Vulnerabilidades y Desastres Socio Naturales de la Universidad de Chile. rictapia@uchilefau.cl 


\section{STATE AND COMMUNITY ACTION WITHIN THE CONTEXT OF HOUSING MANAGEMENT IN THE AFTERMATH OF THE ERUPTION OF CHAITEN, CHILE: TWO DIVERGENT STRATEGIES}

\section{ABSTRACT}

The eruption of Chaiten in 2008 triggered the forced relocation of more than 4000 families to different cities in Chiloe Island and Continental Chile. As of 2015, about 40 per cent of mobilized people have returned to the affected city, which was declared as unsuitable for habitation due to its proneness to natural hazards.

Through the analysis of different State policies and actions, procedures, field analysis, secondary sources and interviews with affected people, this paper concludes that the understanding and dimension of the damage and strategies implemented in relation to housing within the context of this socio-natural disaster are biased, limited and negative. In this sense, risk management has been particularly affected during the reconstruction and resettlement processes since the interests and expectations of locals have not been satisfied.

As for the State strategies intended to address housing management during the Chaiten disaster: Were they adequate? Did they meet the aspirations and expectations of those involved?

This ongoing and unfinished process is suffering from conceptual limitations in terms of understanding, design and management, the result being a serious impact on the quality of life of those affected. Apart from its value as a physical asset, housing was not considered in terms of its intrinsic value.

KEY WORDS: housing, public policies, Chaiten, risk management, volcanic eruption.

\section{INTRODUCCIÓN}

El 2 de mayo de 2008 en la localidad de Chaitén, ubicada en la X Región de Chile, Provincia de Palena, erupcionó un volcán, el Chaitén, del cual no se tenía registro histórico de erupciones previas (ONEMI, 2010) cercano y a $9 \mathrm{Km}$ del pueblo del mismo nombre. Como consecuencia de ese fenómeno hubo intensas emisiones de gases, cenizas y material piroclástico pues el pueblo quedó dentro del área de influencia de volcán, por ello quedó totalmente cubierto de cenizas volcánicas. En los meses siguientes, los lahares provocados por la erupción se sumaron al cauce del Río Blanco el cual pasaba por el borde oriente del pueblo quedando este dividido en dos zonas, situación que se mantiene hasta el presente (Fig. 1).

Chaitén es una comuna constituida por diecinueve localidades, varias de ellas incluso, corresponden a islas y por ende su acceso es solo maritimo. La principal conexión a las localidades se realiza o por la carretera austral o por el mar. Esas condiciones hacen de Chaitén un enclave estratégico y un nodo crítico en la cadena de suministros de productos y servicios que entran y salen de la comuna, más todavía cuando es la localidad que contiene la mayor cantidad de habitantes y el único aeropuerto de la zona. (Falasca et al. 2008) Cumple un rol articulador en ese territorio extremo de la X Región y es la principal entrada a esa parte de la Patagonia chilena.

El impacto de la erupción y el posterior desborde del Río Blanco afectaron a todos incluyendo al propio Alcalde y otro tipo de autoridades locales. La comuna quedó huérfana de toda autoridad local y ella debió operar desde Puerto Montt y otras localidades, tales como Chiloé y Futaleufú al menos hasta el 2013. Estas condiciones y sucesos debilitaron el accionar del gobierno local y su capacidad de reacción y resiliencia al menos hasta el año 2011.

El posterior desplazamiento forzado y rápido de más de 4000 personas de sus viviendas de origen desde una zona de difícil accesibilidad y gran aislamiento como lo es Chaitén, a otras distantes, el mismo 2008, fue un acontecimiento singular en la gestión de riesgos en Chile; no habían precedentes de este tipo, al menos debido a una erupción volcánica (González, 2011; Hubb \& Inbar, 2002; Tapia, 2012). Posterior al desplazamiento, y con el proceso de éxodo aun abierto, marzo 2010, 


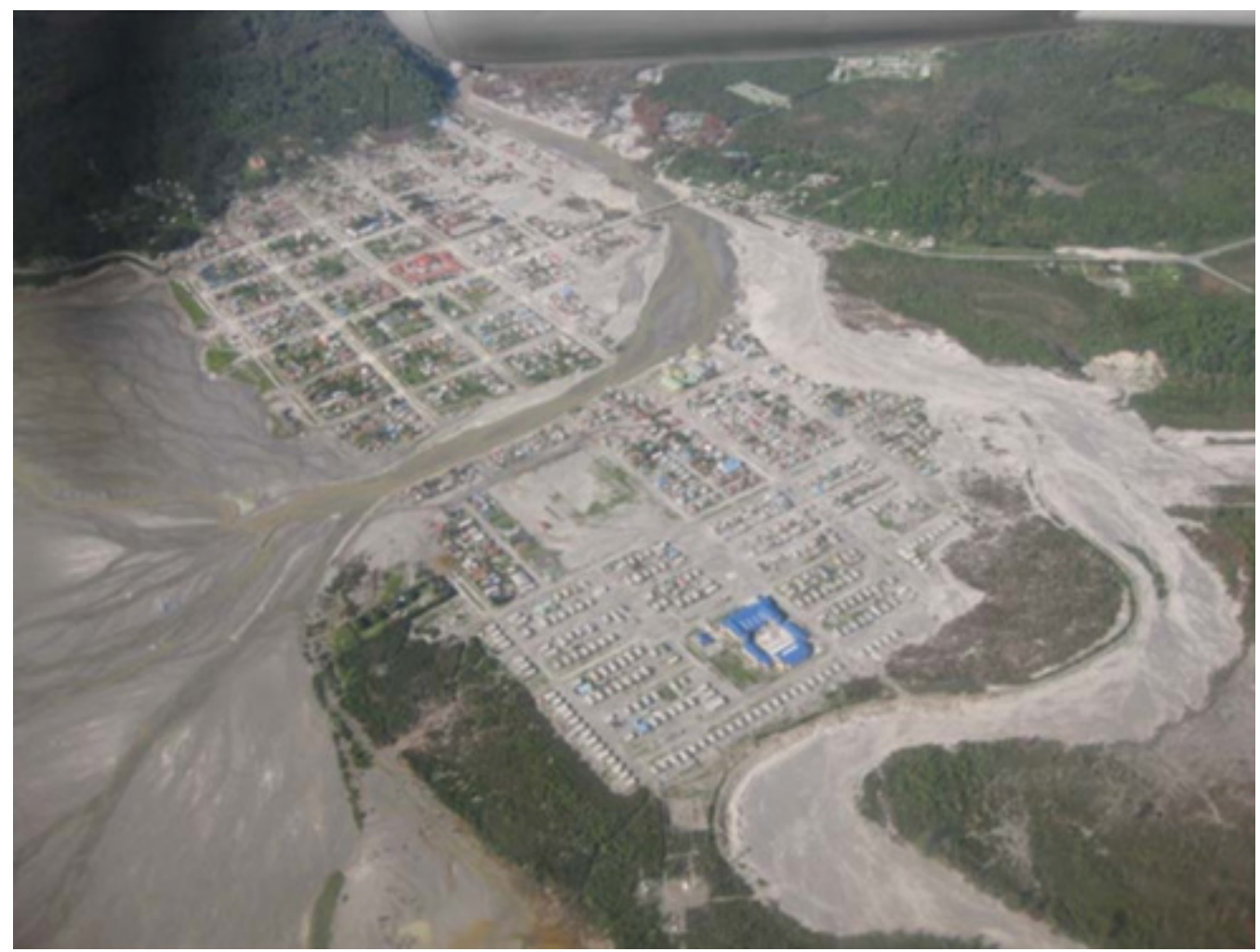

Fig. 1. Vista Aérea de Chaitén post erupción del Volcán Chaitén y con el Río Blanco dividiendo el pueblo en dos partes. Fuente: Consultoría PUC/UACH. 2010.

hubo cambio de administración presidencial y el gobierno entrante, de centro derecha y de signo contrario al que terminaba -de centro izquierdapropuso a los habitantes chaiteninos desplazados que así lo hubiesen deseado, la alternativa de volver a ocupar el pueblo devastado por el impacto de la erupción del volcán, en circunstancias que la administración saliente había resuelto reasentar a la población en una nueva localización, cercana al asentamiento afectado, en vista de la ubicación riesgosa en que aquel quedó. Cabe hacer notar que esta alternativa, la búsqueda de un nuevo emplazamiento y un diseño de plan maestro para esta nueva localización, se desarrolló entre 2008 al 2010 (Fig. 2). En el intertanto, el gobierno de la época entregó subsidios de arrendamiento a las familias desplazadas así como la compra de viviendas a los damnificados que quisiesen, mediante la promulgación de una ley especial- Ley $\mathrm{N}^{\circ}$ 20.385- promulgada por el Congreso Nacional de Chile el 23 de septiembre de 2009, llamada Ley Chaitén (Pontificia Universidad Católica de Chile,
Universidad Austral de Chile, 2008).

El acontecimiento, posterior al éxodo, la compra de viviendas que los habitantes damnificados tenían en Chaitén, tal que con esos recursos, aquellos pudiesen adquirir otra vivienda en otro lugar, seguro, fue una acción, al parecer, no adecuada y poco eficaz. La experiencia de los habitantes, vender en situación de crisis, a un comprador sin competencia como lo era el Estado de Chile y con el precio definido por éste, fue una de la cual no había precedente previo tanto para el mismo habitante como para el Estado. En segundo lugar, no había garantía de que el valor de tasación de las viviendas, sería uno que permitiría al damnificado y desplazado, acceder a otro satisfactor sinérgico de similar o mejor calidad en otra localidad (Max Neef et al. 1986) ¿Cuánto y que perdía el habitante al dejar su hábitat y que obtendría en otro lugar, indefinido, con el valor que el Estado le entregaba por su vivienda?

Más de quinientas personas desplazadas, el mayor grupo, fue trasladado y se le entregó como 
una de las principales opciones para adquirir una nueva vivienda, la localidad de nombre Alerce, un enclave de vivienda social ubicado entre la ciudad de Puerto Montt y Puerto Varas, lugar alejado de ambas ciudades con un rol más bien de asentamiento - dormitorio y con carencias de equipamiento complementario a la vivienda tales como colegios, servicios, conectividad de calidad, de salud y seguridad. Este lugar, Alerce, en el 2015 y como consecuencia de la erupción del volcán Calbuco, estuvo potencialmente afecto a la caída de cenizas.

"Fue un error sacarnos de acá y tal vez esa plata debió ser invertida en limpiar el pueblo", sostenía un vecino retornado a Chaitén el 2014. (Diario El Mercurio, 2014).

La instalación de los pobladores en Chaitén pre desastre 2008, era parte de un largo proceso de lugarización y arraigo debido a su localización y sentido (Augé, 1993; Agnew, 2005; Cresswell, 2004). En el pasado, formó parte de los intentos colonizadores de Magallanes en la parte continental, año 1950 y siguientes y su mar interior (Martinic, 2014). Por otra parte, y dado que la población debió salir forzadamente de su lugar de origen, la participación de ella, en el destino y reconstrucción del pueblo, fue a distancia, irregular y lejana y en plena crisis e impacto de lo vivido y sufrido. Experiencias sobre desplazamientos en cambio, demuestran que la participación, como atributo resiliente, es un medio potente de recuperación

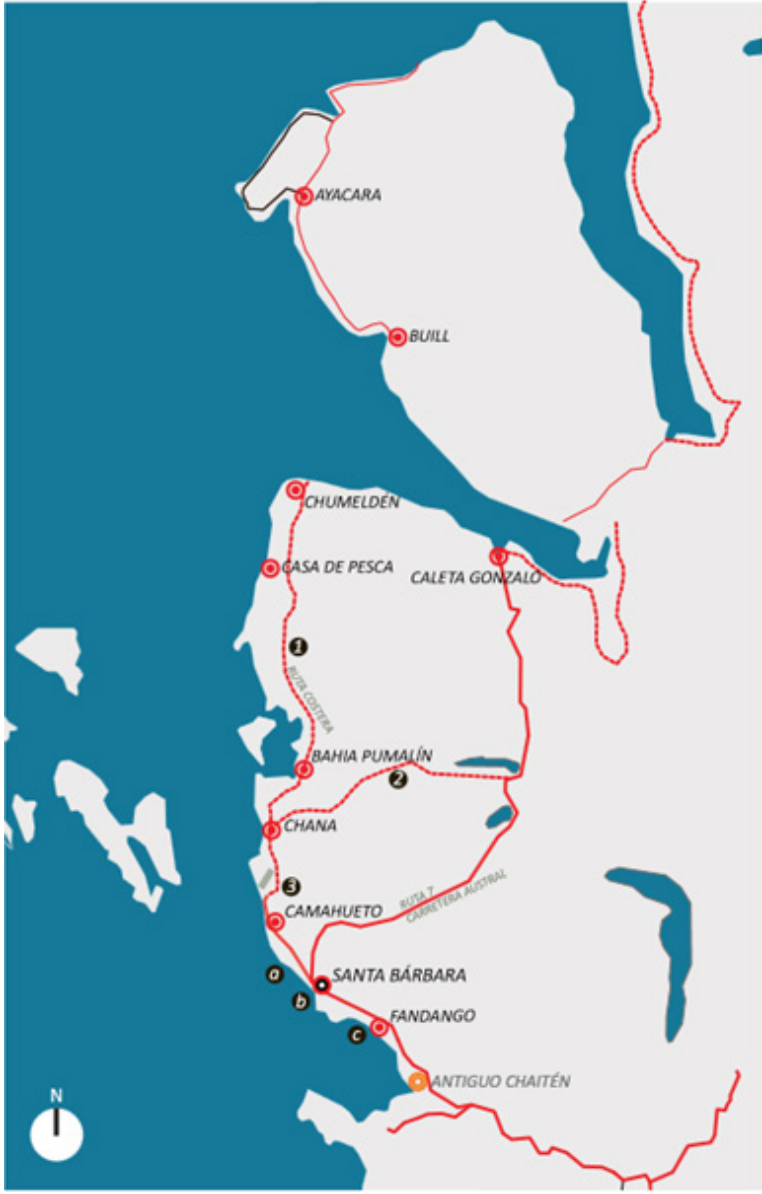

Fig. 2. Plano presentando la ubicación de Chaitén y Santa Bárbara.

Fuente: Consultoría PUC/UACH. 2.
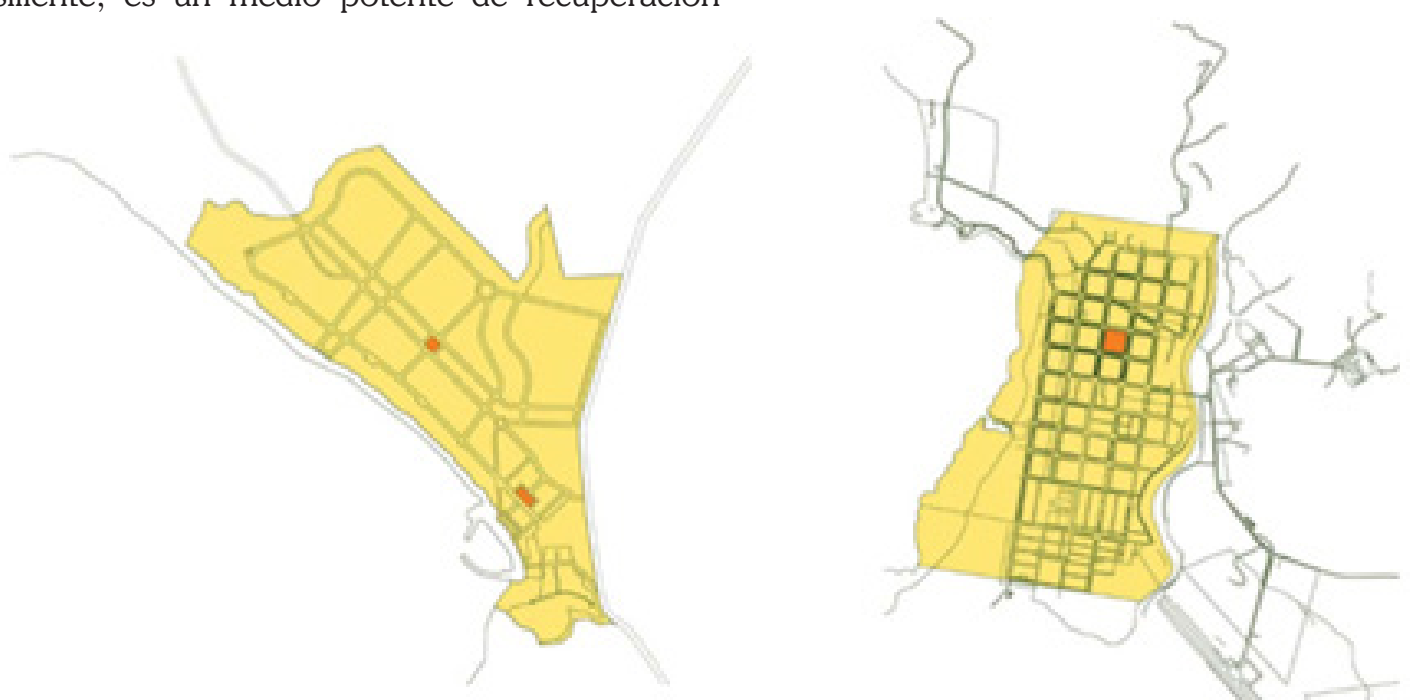

Fig. 3. Planos de Santa Bárbara y Chaitén (pre erupción). Fuente: Consultoría PUC/UACH. 2010. 


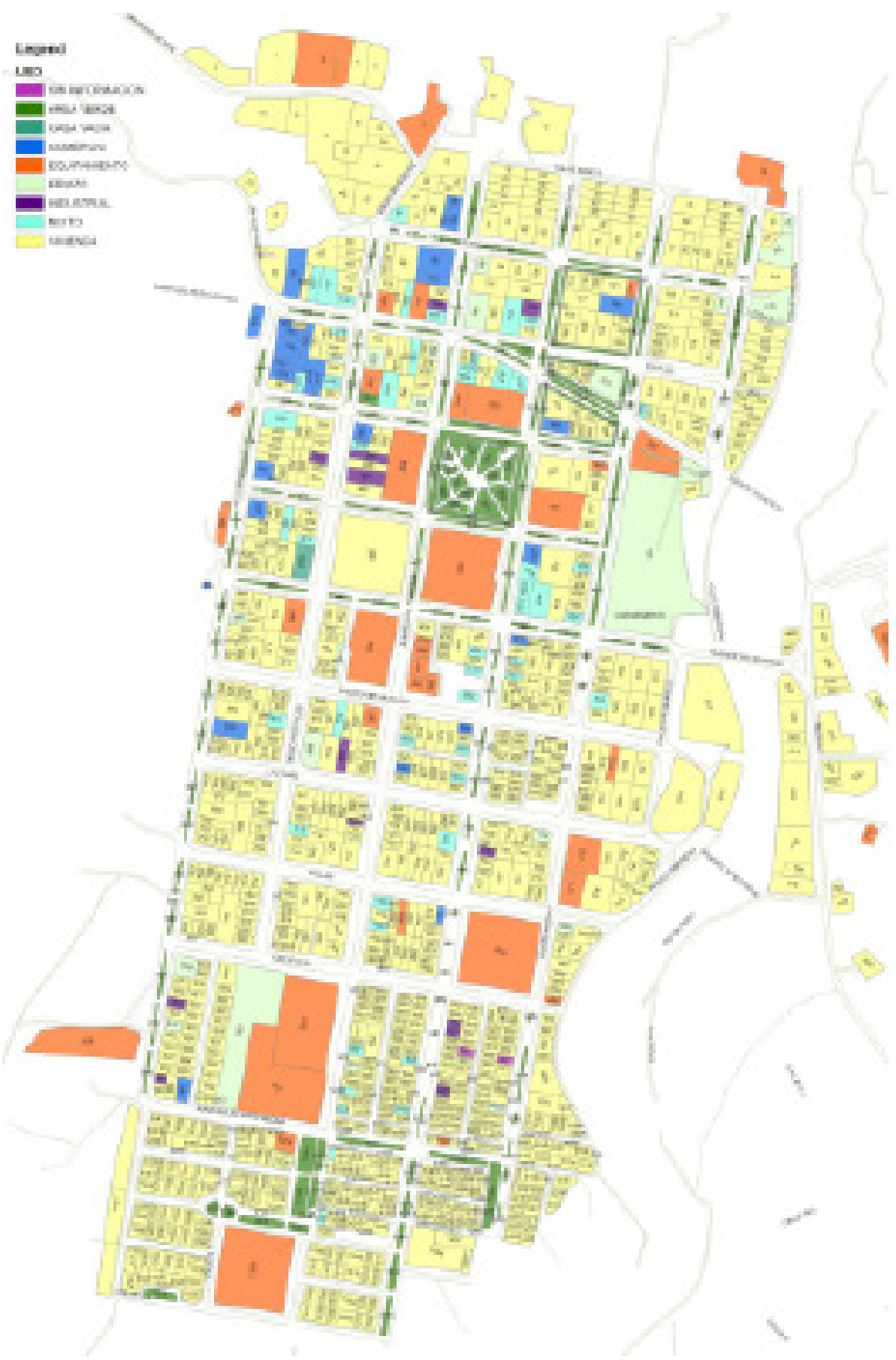

Fig. 4. Plan Regulador de Chaitén Pre erupción. Fuente: PUC, 2009.

para reconstruir áreas y lugares devastados (Moreira, 2006; Programa CYTED, 2003; Cutter, et al. 2008; Chardón, 2010). Un desastre y su manejo, puede ser una oportunidad para elevar el nivel de vida de la población (Fig.3 y Fig. 4).

El éxodo obligado e intempestivo, disgregó al colectivo de población chaitenina a localidades de Chiloé, Puerto Montt, Futalefú, Palena y otras 
localidades menores. En Chiloé y Puerto Montt un vez ubicados allí, empezaron a organizarse para mantener una mínima cohesión e información alusiva a un futuro incierto. A las familias damnificadas en un primer momento, se les entregó subsidios para arrendamiento, mientras ellas se decidían a vender sus viviendas o no resolvían que tipo de decisiones tomarían respecto de viviendas en donde asentarse y comprar.

Los habitantes, desde el año 2010 a la actualidad han seguido regresando a Chaitén. De 7.062 habitantes que tenía la comuna el 2008, a abril 2013 habían regresado 3.424 en total. De los 7.062, el segmento etario mayoritario, un $24,06 \%$ estaba constituido por personas entre 45 a 60 años. De los 3.424 regresados al 2013, el segmento etario mayoritario en cambio, un $36,13 \%$ era de una edad comprendida entre los 35 a 59 años. Las cifras demuestran que los retornados son más jóvenes que los habitantes existentes previos a la erupción. Al 2012, además, aun habían 1.199 viviendas inhabitadas (Diario La Tercera, 23/04/2013).

Una de las dimensiones que falló en el tratamiento de la gestión del riesgo en Chaitén, fue la comprensión limitada del hábitat y su valorización en el diseño del plan y en las políticas públicas implementadas para atender el fenómeno en toda su complejidad.

\section{METODOLOGÍA}

Se utilizó revisión de antecedentes primarios y secundarios de diverso tipo, visita y observación especializada de campo, notas y entrevistas grupales y personales y talleres de discusión con habitantes de Chaitén e informantes claves de la comuna y la región, en el año 2012, todos ellos damnificados y retornados de vuelta a Chaitén, diferenciando en ese instrumento, la dimensión estructural, de la subjetiva y la de políticas públicas (Arroyo \& Sádaba, 2012), previa definición de un marco conceptual acerca de la gestión del riesgo, los fenómenos y desastres socionaturales, en particular, las erupciones volcánicas y el hábitat popular en esos contextos.

Las entrevistas, 17 en total, se realizaron en Puerto Montt, a funcionarios municipales y en Chaitén, al propio alcalde, habitantes hombres, mujeres, adultos y representantes de organizaciones sociales y del colegio-internado de la ciudad.

Posteriormente se transcribieron las entrevistas y se hizo análisis de discurso acorde a las referencias conceptuales alusivas al problema estudiado, agrupando el análisis en dimensiones acorde al marco de referencia.

\section{MARCO CONCEPTUAL}

En el diseño de políticas públicas puede operar un enfoque racional, $u$ otro, en que se supone que los actores proceden en acuerdo a fines y valores, los incorporan y se producirán resultados que corresponderán al enfoque adoptado. Las políticas públicas no son neutras, sino incrementales. Ellas también responden a factores críticos de la contingencia política, como por ejemplo en Chile, los cambios en las políticas educacionales como consecuencia de la presión del movimiento estudiantil. Así, un conjunto de políticas públicas debiera apelar más bien a una racionalidad social, que sólo a factores determinados por el beneficio económico de su aplicación. (Olavarría, 2007). Sin embargo, la instrumentalidad que las políticas públicas han tenido, ha sido una de tipo tecno-instrumental y que utiliza un enfoque tecnocrático para atender problemas públicos. En este enfoque, el Estado renuncia a desarrollar intervenciones tecno - políticas, por ejemplo, en el mercado de suelo urbano y en la localización del mismo (Raposo, 1998) e instala con ello, un repliegue de los beneficiarios de tales políticas de vivienda, hacia el interior de éstas, fomentando a un perfil individualista que reniega de lo colectivo o comunitario (Besoain \& Cornejo, 2015).

En el sector de las políticas habitacionales y del urbanismo, Chile adoptó desde mediados de 1980, y hasta el presente, un diseño y gestión, más bien privado y subsidiario en estas áreas del desarrollo nacional y que ya está internalizado en la ciudadanía (Gilbert, 2003; Hidalgo, 2005; MINVU, 2013; López et al. 2014), por ello, en la gestión del tratamiento de las viviendas en Chaitén, primó esa forma de actuar.

La vivienda, el componente más importante de capital físico para los pobres, y si bien como tal, no tan significativo para salir de estados de pobreza, es condición previa necesaria para acumular otros activos. (Moser \& Felton, 2009). Posee atributos de resiliencia, principalmente representados en la edad 
y características del parque habitacional construido (Cutter, et al. 2008). Además de ser consumida, es vivida, es hogar, ordenadora del mundo de los sujetos (Giglia, 2012), morada (Cortés, 1995; Bourdieu, 2001). Max Neef et al. (1986) la define, como un satisfactor sinérgico de necesidades existenciales y axiológicas y su producción, puede ser concebida como una actividad económica más. (Merton et al. 1963). Este modo de concepción de la vivienda, el de los autores citados, era el representativo de los habitantes de Chaitén hasta antes de la erupción pues solo en el sector sur del poblado se ubicaba el único conjunto de vivienda social construido mediante las políticas públicas de los últimos veinte años. Las demás viviendas del pueblo, habían sido construidas por los habitantes mediante la autoconstrucción y autogestión. Ello implicaba que tales habitantes no habían experimentado el modelo de provisión habitacional que rige a Chile desde mediados de los años setenta y por ende podían desconocer su operatoria y diseño.

La vivienda, podría ser también un problema público, cuando es una muestra de carencias en la sociedad. (Olavarría, op cit.). Para el caso chileno, estudios de opinión demuestran que al menos desde el 2008 al 2013, la vivienda no es uno de los problemas públicos para los chilenos (Public Affair, 2008, 2012). Esta constatación permite aseverar que a pesar de haber sufrido un devastador terremoto como lo fue el de $8.8^{\circ}$ Richter en el 2010 , la ciudadanía considera otros los problemas del país tales como la delincuencia, la inseguridad, la salud y la falta de trabajo identificados como los más graves. Esta situación -de que en el foco de los problemas públicos de Chile no está la vivienda- podría ser uno de los factores que hace que aquella, a pesar de su influencia en la calidad de vida del individuo, no sea percibida en su importancia, por ello, desde éste satisfactor, no se expresa malestar público y presión social hacia el Estado. Los habitantes de Chaitén no tenían como prioridad la vivienda antes de la erupción de volcán y el Estado tampoco tenía experiencia de cómo tratar la vivienda en cuanto problema público en situación de crisis por desastres socionaturales y en reasentar un gran volumen de población con la complejidad además del aislamiento geográfico, de conectividad y dificultades operativas para resolver todo ello en un tiempo breve.

Según Haramoto (1998) a partir de
Vancouver76, la vivienda se definió como sistema, integrado por el suelo en donde se aquella se ubica, la infraestructura y servicios complementarios dentro de un contexto cultural, socio-económico, político y medio físico ambiental. Tales componentes se relacionan y condicionan entre sí. Tendría además, una comprensión escalar y de lugar y poseería atributos de variado tipo. También se puede entender como proceso, pues su resolución se inicia con la etapa de prospección, continuando con la de planificación, diseño, construcción, asignación uso y administración (Haramoto, $O p$ cit.). En tal proceso participan múltiples actores: los propios habitantes, el sector público, privado y técnico profesional, entre los más relevantes.

Forma parte del hábitat y el habitar estar localizado - (Giglia, Op cit.; González, 2009), y de la llamada "producción social de hábitat” en Latinoamérica (Ortiz, 1998, RED XIV.F Tecnologías Sociales y Producción Social del Hábitat, 2007).

La vivienda y la arquitectura que habitaban -y que habitan - los chaiteninos, era en su mayoría, vivienda y arquitectura popular de al menos cuatro generaciones. Esa arquitectura, se asocia a una denominada tradicional, la que se ha desarrollado fuera de las corrientes de arquitectura "culta" y de su historia. Una de sus principales peculiaridades es que se transmite mediante vía oral y heredada (CIAT, Universidad Politécnica de Madrid, 2012), no está determinada por moldes culturales formales, para el caso, la arquitectura de autor. Es también coherente con la realidad cultural y social de los individuos, sus sistemas de valores y base económica, entre otros factores (Rapoport, 1972; Turner, 1972; Tiburcio, 2008).

El hábitat popular, en donde se inscribe tal arquitectura, remite a las formas de habitar y la estructura social que se va constituyendo en el tiempo. (Sáez et al. 2010; Chardón, 2010). No todo proceso de hábitat popular es informal (De Soto, 1987; Di Virgilio et al. 2014) pues el hábitat informal remite al ordenamiento jurídico vigente en un determinado momento histórico. El pueblo de Chaitén, entonces, es parte del hábitat popular $y$ formal. Fue fundado oficialmente e incluso, contaba con un Plan Regulador, si bien caduco, 
al momento de la erupción, lo que se constituía como otro factor de riesgo, desde las normas y sus diseñadores (Lhumann, 1998), pues daba cuenta de estar incluido y reglado dentro de la estructura de asentamientos poblados de la nación.

El ser humano no solo reacciona frente al ambiente o entorno físico y sus estímulos si no que ambos se influyen y se cambian mutuamente (Proshansky, et al. 1983; Tuan, 1974), por ello variables del diseño arquitectónico interiores de la vivienda tales como dimensiones, superficie, circulaciones, sociopetividad (características de los espacios internos facilitadores de interacción entre personas), conectividad, vigibilidad, seguridad, profundidad, entre otras, podrían tener interrelación con atributos de habitabilidad, tales como placer, activación, control, significado, funcionalidad, operatividad y privacidad (Landázuri \& Mercado, 2004). Las viviendas de Chaitén al ser diseñadas por su propios habitantes eran representativas de tales atributos y satisfactores.

A través de las interacciones diarias que en esos espacios se dan, las personas aprenden a entender su "lugar" y su valor en la sociedad (Duran-Narucky, 2008). Al respeto, diversos autores prefieren emplear el concepto de lugar, para representar la relación entre lo espacial y lo social. Lugar, sería, tiempo en el espacio, pues alude a un proceso de lugarización que surge sobre la base de la experiencia y a la asignación de sentido (Muntañola, 1973). El espacio y las personas constituyen el ambiente de los sistemas sociales, convirtiéndose en lugar cuando es observado y adquiere significación, de ese modo, las viviendas son contenidos de un proceso constructivo constante de sentido y memoria (Kellett, 2002) tal como lo eran las viviendas de los chaiteninos.

Un conjunto de rasgos propios del espacio socializado, para el caso, el lugar son, entre otros, su exclusividad, en cuanto a que, cualquier trozo de espacio es único; la existencia de límites por la práctica social, que implica que éste no es un hecho espacial con repercusiones sociológicas, sino un hecho sociológico con forma espacial y el que los contenidos de las relaciones sociales se fijan dentro de un espacio determinado (Simmel, 1939). Son el resultado de múltiples decisiones en un contexto de temporalidad (Goodman, 1972) más todavía, en un territorio alejado y desconectado de su centro de gravedad representado en la centralidad de la gobernabilidad chilena como lo es Chaitén.

La expresión simbólica del espacio, posibilita la estabilidad de los grupos, facilitando su identificación, sentido de pertenencia y asignación de valor. La permanencia en un sitio determinado favorece la formación de una imagen ambiental que posee identidad, estructura y significación, y por tanto, puede ser comunicada al interior de un sistema social (Norberg-Schultz, 1983). El espacio como lugar adquiere un destino cuando es reconocido, diferenciado y apropiado por un grupo con el propósito de transformarlo en un ámbito específico donde efectuar comunicaciones con un sentido particular. (Sepúlveda, et al. 1999; Gómez, 2009). Comprendido de este modo el proceso de constitución de Chaitén, en cierto modo un enclave isla con respecto a otros centros poblados, por ejemplo, en relación a Puerto Montt o el mismo Chiloé, lo hacían un lugar de un colectivo o comunidad viviendo en conjunto esa identidad, límites y características propias de la lejanía y el distanciamiento del país y su historia. La lejanía y el proceso de su ocupación se originaron desde más el sur y por la conformación de los límites territoriales particulares de la Patagonia chilena.

\section{RESULTADOS}

El tratamiento de la vivienda y su valoración para los habitantes de Chaitén.

Las viviendas de Chaitén, habían sido construidas por sus propios habitantes. El proceso de habitar fue en parte, una consecuencia de sobrevivir en esas inhóspitas latitudes utilizando recursos provenientes del trabajo rural y la búsqueda de mejores condiciones de calidad de vida en el pueblo que comenzaba a asentarse, proceso constituido en décadas. La cultura constructiva y la arquitectónica se traía de Chiloé o del modo de vida rural propia del extremo sur chileno y su clima.

...es que Chaitén se pobló desde Chiloé $y$ desde la frontera con Argentina. Entonces vinieron de todos lados. Chaitén se caracteriza, su identidad para mi era justamente la diversidad, porque éramos gente venidas de todos lados, especialmente chilotes, mucha costumbre chilota, tanto en el aspecto de la construcción como de costumbres del diario 
vivir $^{2}$

Entonces la gente buscaba un lugar donde embarcarse en sus lanchas todo el día, entonces la gente colocó el puerto, un par de casas y así empezó a crecer el pueblo, pero la gente seguía viviendo en el campo porque su sustento venia del campo. Entonces tenían una casita en Chaitén porque los chicos tenían que venir al colegio, pero ellos vivían en el campo ${ }^{3}$

"Chaitén me hizo crecer enormemente en lo profesional porque sentía que era, lo dice mi marido muchas veces, es que como jugar a la gran capital, porque había todo por hacer"4.

\section{Rol del Estado}

El Estado y sus políticas públicas hasta antes de la erupción, fueron aportado al diseño y configuración urbana, junto al equipamiento vial, infraestructura de servicios tales como el aeropuerto, único en la zona y que trasladaba pasajeros desde Puerto Montt, el muelle de embarco y desembarco para las barcazas en donde se transporta la mayor parte de la gente, equipamiento policial, colegios, puentes y provisión de energía, entre las más relevantes. En ese contexto, las políticas públicas alusivas a la vivienda solo habían llegado al lugar antes del 2008, en un único conjunto de viviendas sociales que quedaron ubicadas en el lado sur del pueblo, lado declarado inhabitable post erupción. Por ello, los habitantes no habían tenido participación en la gestión o acceso a sus viviendas mediante programas del Estado. Había un desconocimiento de ello.

Se supo que recibiríamos subsidios (670 UF) para comprar casas y los precios se dispararon de los 9 a los 14 millones de pesos, en que la mayoría de los chaiteninos solo nos alcanzó para comprar casitas en la población Los Alerces- negocio amarrado con la

2 Entrevista a ex profesora de la Municipalidad de Chaitén, realizada por equipo del Centro de Investigación en Vulnerabilidades y Desastres Socionaturales (CIVDES). Abril, 2012.

3 Entrevista a funcionario de la Municipalidad de Chaitén, realizada por equipo del Centro de Investigación en Vulnerabilidades y Desastres Socionaturales (CIVDES). Abril, 2012. inmobiliaria Geiser que despertó suspicaciasy ahi estamos, lejos de la ciudad, hacinados en un barrio peligroso donde el día que llegué mataron a un cabro en la puerta de mi casa. ${ }^{5}$

El proceso del manejo de la vivienda para los chaiteninos, al 2015, aún no termina. El pueblo sigue dividido en dos partes y todavía no se toman decisiones- trabajadas con la comunidad y las autoridades locales- en cuanto al quehacer con tales condiciones de hecho. El retorno sigue en desarrollo y los que vuelven son los más jóvenes, como ya se indicó.

Y si bien un $75 \%$ de las viviendas existentes, pertenecen al fisco (Diario La Tercera. 23/04/2013) surgen paradojas del proceso vivido.

"Lo que tenemos hoy es un grave problema de falta de viviendas, el mayor obstáculo para el desarrollo del pueblo", señalaba Paula Forttes, Delegada Presidencial para la reconstrucción de Chaitén en mayo de 2014 en su visita al lugar (Diario El Mercurio, 2014).

Dado que el proceso aún está en desarrollo, no se ha aprendido o tal vez, internalizado por todos los actores, habitantes y Estado, que lecciones deja este suceso. En cuanto a relevar aprendizajes que puedan ser incorporados en la gestión del riesgo y el ordenamiento del territorio y la complejidad que posee.

...no está demás recordar que las posibilidades de desarrollo de los últimos años, han sido disminuidas por políticas públicas no del todo efectivas, ya que la cambiante dirección del Estado para enfrentar esta situación, ha relevado Chaitén como ejemplo de lo que no se puede volver a repetir en términos de politicas públicas (Ministerio de Interior y Seguridad Pública. Gobierno de Chile, 2014).

En el mes de mayo 2015, el Volcán Chaitén ha estado presentando un cierto nivel de inestabilidad

4 Entrevista a ex profesora de la Municipalidad de Chaitén, realizada por equipo del Centro de Investigación en Vulnerabilidades y Desastres Socionaturales (CIVDES). Abril, 2012.

5 Revista El Periodista. Se vende Chaitén. Los intereses que amenazan la reconstrucción del pueblo. 23 julio 2010. Año 8, $\mathrm{N}^{\circ}$ 195. Santiago, Chile. Entrevista a un habitante desplazado de Chaitén. 
que ha obligado a las autoridades a calificar su situación en la categoría de alerta de color amarillo (entre tres colores, rojo, naranja y amarillo, que los organismos técnicos utilizan para calificar el nivel de riesgo y alerta en volcanes en Chile). No hay ningún instrumento público que indique que hacer en caso que el volcán vuelva a erupcionar, evidencia que demuestra una vez más, la porfía del Estado en no decantar y aprender de los errores cometidos y por ello estos acontecimientos evidencian una falta de estrategia conceptual en la comprensión del problema y sus derivados.

\section{El concepto de lugar}

Dada la ubicación de Chaitén, su emplazamiento entre cerros y el mar interior, su tamaño, recorrible peatonalmente en su totalidad, rodeado por un rio y con una población que vivía de la pesca, los servicios turísticos, la producción ganadera rural y los servicios públicos, sumada a su aislamiento geográfico y cantidad de población, se fue configurando una identidad singular que en cierto modo posibilitó una identidad y reconocimiento de una comunidad. Al ser expulsados a la fuerza y ubicarse en otros lugares extraños y desconocidos los damnificados pudieron, por comparación, ponderar lo que perdían al dejar su lugar de origen (Fig. 5 y Fig.6).

Allá me transformé en una buena cocinera, jajaja. Pero además allá lo rico,... era que tú podias ir a tu casa a almorzar, a tomar once. Había tanta vida familiar y acá no, acá nos hace las distancias nos hace estar super lejanas ${ }^{6}$

Los habitantes del pueblo de Chaitén fueron realojados en distintos territorios, geografías y lugares. Algunos en localidades más cercanas, como los poblados de Futaleufú y Palena, otros en poblados y pueblos de la isla de Chilóe, también en Puerto Montt y su periferia y particularmente, en la localidad de Alerce, un poblado ubicado en áreas rurales de esa ciudad. Allí, fueron ubicados cerca de 500 familias.

6 Entrevista a ex profesora de la Municipalidad de Chaitén, realizada por equipo del Centro de Investigación en Vulnerabilidades y Desastres Socionaturales (CIVDES). Abril, 2012.

7 Mujer chaitenina. Entrevista grupal realizada por equipo "las casas eran muy chicas en Alerce, sabe que andaba...todos los días lloraba, todos los días"

La escuela internado y liceo, lugares de encuentro de la comunidad y activos de capital físico (Moser \& Felton, Op cit.), fueron dos pérdidas de servicios complementarios que rápidamente y post erupción, se reestablecieron en otra localidad cercana y segura. En Palena, por ejemplo, ya en el 2009, por iniciativa de un grupo de profesores desplazados, se reinstaló y comenzó a operar de modo refundido, la escuela y liceo.

"Alli, con la mejor voluntad de las autoridades locales, de la dirección escolar, de sus profesores y docentes, comenzó la difícil tarea de adaptarse, compartir espacios, optimizar el uso de los escasos recursos disponibles, etc"

Al respecto y a partir de la reinstalación espontánea del colegio en otro lugar geográfico, se reafirmó el atributo de ingenio y rapidez, propios de la recuperación en el triángulo de la resiliencia, cuestión que se le criticó al Estado por la comunidad de profesores, parte del capital social de Chaitén. El alcalde, como poder político local, también damnificado, se sumó, hasta el presente, a los atributos resilientes inherentes a la comunidad.

"Eso es como un polo de atracción habiendo escuela" (H2)

En este proceso de reinstalación, hubo, por cierto, muchas promesas de autoridades politicas nacionales, regionales y provinciales que, lamentablemente, hasta el dia de hoy, no se han cumplido: entre otras, conteiner, para habilitarlos como salas de clase, computadores, teléfonos, equipamientos para educación física y música, biblioteca, etc." 9

del Centro de Investigación en Vulnerabilidades y Desastres Socionaturales (CIVDES). Abril, 2012.

Ibidem.

Ibidem 


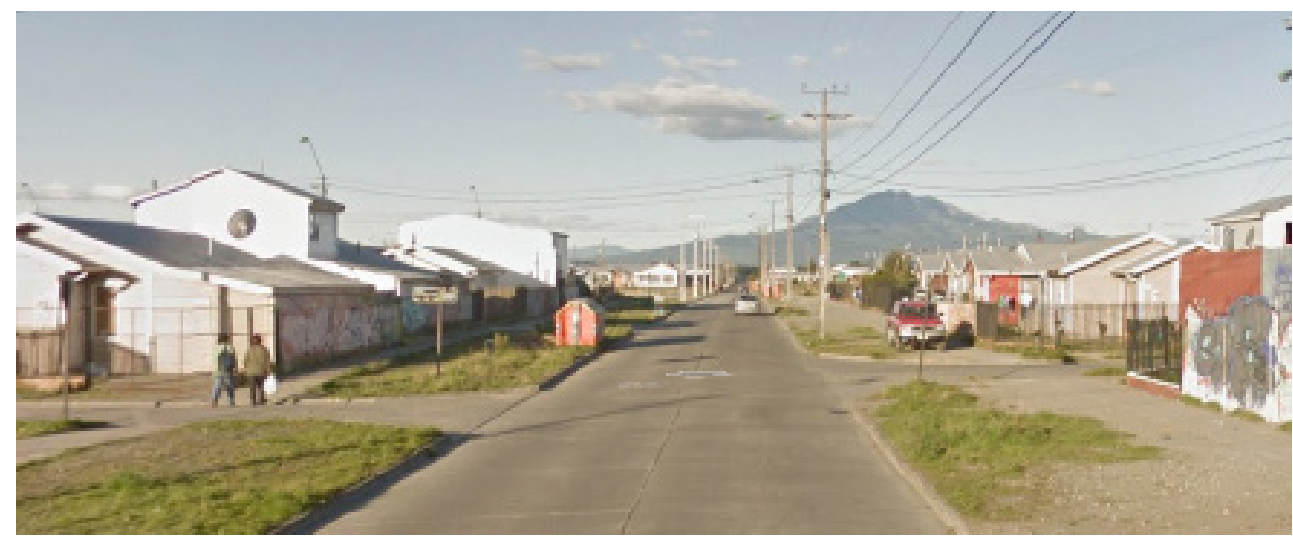

Figura 5. Vista de una calle de la localidad de Alerce, Puerto Montt con el Volcán Calbuco al fondo. Fuente: Google maps. 2015.

\section{Rol del gobierno local}

El gobierno local representado en sus autoridades post erupción no tuvo reacción inmediata al acontecimiento, pues fue un damnificado más en ello. Sin embargo, una vez evacuados los habitantes, el alcalde regresó y empezó a tomar protagonismo creciente. Apoyó a los que habían decidido retornar junto a un grupo de vecinos que resolvieron quedarse y oponerse al éxodo definitivo. Un grupo de familias, no más de cien personas, volvió para instalarse en la parte sur del pueblo dividido en dos partes por el río, sector este último sin red de agua potable, alcantarillado y red eléctrica. El alcalde, en contra de las decisiones del gobierno central, optó por apoyar esa reinstalación asumiendo la responsabilidad de sus actos.

porque acá puedo manejar el tema, porque tengo el plan de contingencia, el plan de evacuación, coloqué un motor de luz para

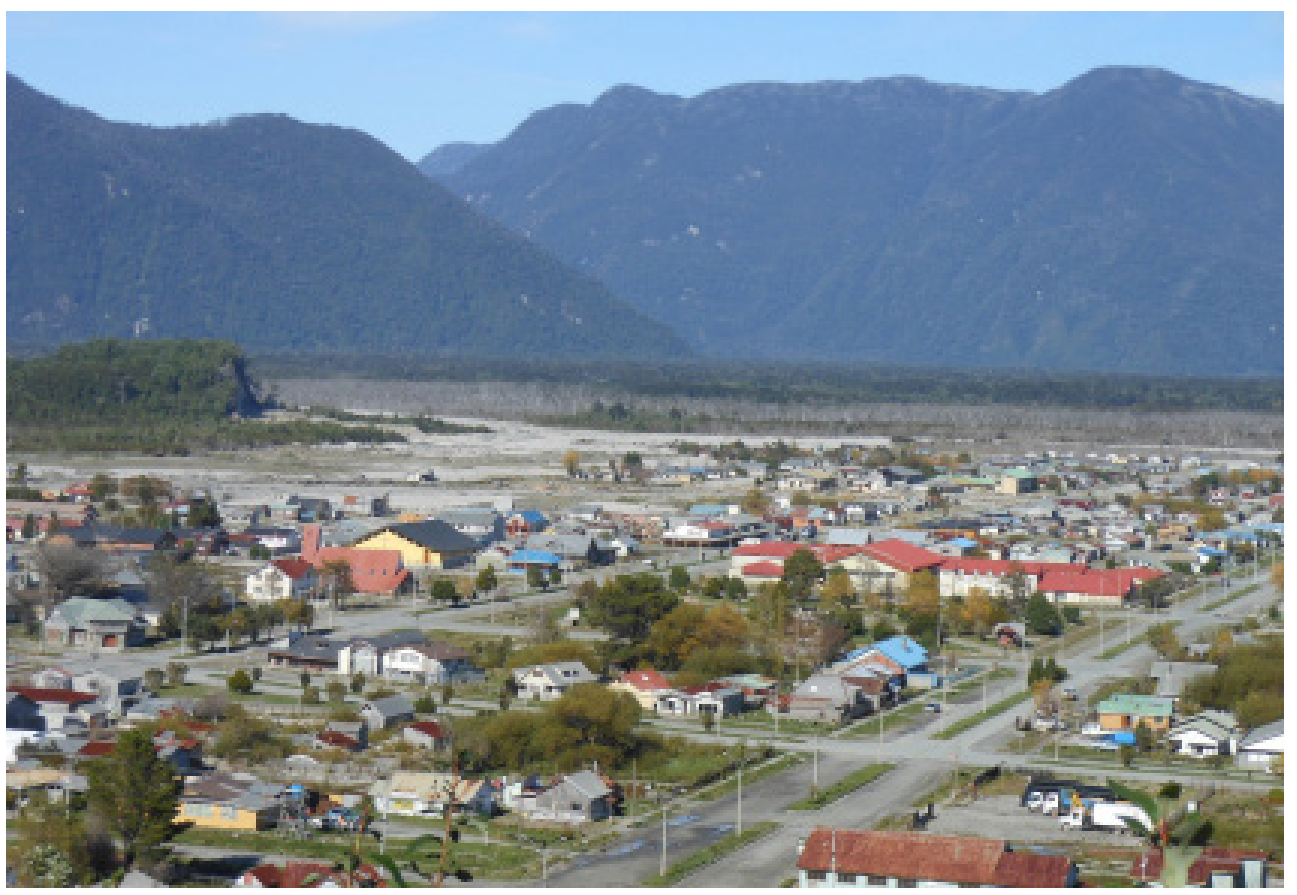

Figura 6. Vista de Chaitén post erupción. Fuente: Autor. 
emergencia. La empresa privada no se hace cargo de la catástrofe ni de la luz ni agua. Entonces siempre nosotros como municipio desde que llegaron las primeras personas 10 familias hemos empezado a hacer acciones de poder ir manejando este cuento, con los recursos que tiene el municipio ${ }^{10}$

Los profesores del único internado que tenía Chaitén y que ya está en pleno funcionamiento nuevamente, también adoptaron una postura colectiva y proactiva para mantener viva la comunidad y volver a reproducirla una vez superada la emergencia y el destierro forzado. Antes de volver a Chaitén, parte de la comunidad escolar, representada en sus profesores en algún momento confiaron en la alternativa de una nueva relocalización para la ciudad, un área rural a $6 \mathrm{~km}$ de la localización de Chaitén, llamada Santa Bárbara.

Entonces agarramos todos nuestros temas y nos fuimos a Palena, a la cordillera, allá teníamos un colegio que era de Chaitén pero que estaba desplazado allá, lo hicimos funcionar dos años en Palena, éramos como los allegados, incluso para los niños era complejo, fue realmente doloroso y estaba la lucha por volver, volver, volver ${ }^{11}$

Acá estamos porque estamos a un paso del lugar donde se proyecta reconstruir nuestro pueblo. Nosotros, al igual que algunas autoridades, políticos, ecologistas, urbanistas, empresarios, queremos participar comprometida y activamente en el sueño de imaginar un nuevo Chaitén ${ }^{12}$

En cuanto a la vivienda y el hábitat, la

10 Entrevista a Alcalde de la Municipalidad de Chaitén, realizada por equipo del Centro de Investigación en Vulnerabilidades y Desastres Socionaturales (CIVDES). Abril, 2012.

11 Entrevista a ex profesora de la Municipalidad de Chaitén, realizada por equipo del Centro de Investigación en Vulnerabilidades y Desastres Socionaturales (CIVDES). Abril, 2012.

12 Extractado de carta del Consejo de profesores del Liceo Italia de Chaitén, reinstalados en Palena, al Alcalde de la Municipalidad de Chaitén. 13 abril 2009.

13 Entrevista a hombre 1, habitante de Chaitén, realizada por equipo del Centro de Investigación en Vulnerabilidades y fracasada reinstalación del poblado de Chaitén tuvo un proceso de gestión incompleto, inconcluso y limitado. Incompleto pues, la racionalidad tecnoinstrumental del Estado, determinó la localidad de Santa Bárbara como la nueva localización, en ausencia de la comunidad originaria, desplazada y dispersada en múltiples localidades.

Y yo me acuerdo que no sé po, con Santa Bárbara nosotros hacíamos, que nos mostraban los arquitectos una cosa súper acá qué sé yo, esa ciudad maravillosa del futuro y qué sé yo, la nueva Suecia, cachai. Pero nosotros decíamos: ¿y a la gente le interesará esta cuestión, sabrán ellos si nosotros hemos conversado cuáles son las necesidades de la gente? ${ }^{13}$

“...otro de los elementos que yo creo que hicieron fracasar el tema de Sta. Bárbara, es la lentitud de la toma de decisiones, el Estado no estaba capacitado para actuar rápidamente ante la emergencia"14

No era imposible que lo hicieran, porque no era un problema de ingeniera ni de dinero pero sucedía que la gente, nadie quería irse a Santa Bárbara. Entonces sucede que los asentamientos humanos no se hacen, suceden, son espontáneos, no se hacen por ley o por decreto ${ }^{15}$

“... no hubo nunca consentimiento de parte de la gente de decir, nunca hubo credibilidad, ni confianza desde la ciudadanía. Ni credibilidad, ni confianza en ese proyecto" 16

...derechamente en el tema Santa

Desastres Socionaturales (CIVDES). Abril, 2012

14 Entrevista a funcionario de la Municipalidad de Chaitén, realizada por equipo del Centro de Investigación en Vulnerabilidades y Desastres Socionaturales (CIVDES). Abril, 2012.

15 Entrevista a hombre 1, habitante de Chaitén, realizada por equipo del Centro de Investigación en Vulnerabilidades y Desastres Socionaturales (CIVDES). Abril, 2012.

16 Entrevista a hombre 2, habitante de Chaitén, realizada por equipo del Centro de Investigación en Vulnerabilidades y Desastres Socionaturales (CIVDES). Abril, 2012 
Bárbara han pasado muchos personajes, mucha historia, mucho cuento pero yo sé que existe una maqueta inmensa en Santiago hecha por no sé qué Universidad o arquitectos de lo que era Santa Bárbara para cinco mil personas, con edificios públicos, escuelas, era una ciudad y ahi está, después la más chica, estuvo hasta en unos concursos a nivel nacional e internacional de la escuela de arquitectos y tampoco quedó en nada ${ }^{17}$

El intento de reubicación de Chaitén en la localidad llamada Santa Bárbara quedó inconcluso. No se llevó a cabo en su totalidad y también fue limitado porque la comprensión del hábitat dañado a recomponer, fue destacada por los arquitectos encargados de la reconstrucción, solo a su dimensión físico espacial, ignorando condiciones subjetivas del proceso hasta el día de hoy, en desarrollo (Gómez, Op cit). Los testimonios de los habitantes muestran que no se sintieron efectivamente partícipes del proceso de imaginar y concretar un nuevo emplazamiento y arquitectura representativos. Los lugares destruidos por el impacto del volcán no se podían recuperar con una nueva ciudad realizada por otros pues esa otra ciudad no podía trasladar las vivencias de los sentidos de la vida experimentados en Chaitén como señala Fu Tuan (1974) en su obra Topofilia.

Porque una de las cosas que más veíamos con la gente era la participación. Porque, en definitiva, cómo estábamos previo a las elecciones la gente lo que quería era que hubiese una decisión más de Estado que de Gobierno. Porque si cambia el gobierno, ¿qué iba a pasar? ${ }^{18}$

"Porque ocupar el subsidio significaba establecerse en una ciudad que no era

17 Entrevista a hombre 1, habitante de Chaitén, realizada por equipo del Centro de Investigación en Vulnerabilidades y Desastres Socionaturales (CIVDES). Abril, 2012.

18 Entrevista a funcionario de la Secretaria Regional Ministerial del Ministerio de Vivienda y Urbanismo, Región de Los Lagos, diciembre 2012 realizada por equipo del Centro de Investigación en Vulnerabilidades y Desastres Socionaturales (CIVDES).

19 Entrevista a funcionaria de la Municipalidad de Chaitén, realizada por equipo del Centro de Investigación en Vulnerabilidades y Desastres Socionaturales (CIVDES).
Chaitén"19

"Hoy cuando te entregan un subsidio no te dicen dónde quieres vivir. Agarran 200 casas y las meten en una bolsa y metî la mano y te tocó la n 45 "20

Dado que no había experiencia previa desde la institucionalidad en temas de desplazamientos forzados y reasentamientos forzosos, se fue improvisando la gestión sobre la marcha en un contexto, como ya se señaló, de un Estado reducido, y en un modelo de economía neoliberal que se desliga de la protección de su sociedad civil (Salazar, 2009).

le vendió al Estado, y hoy día viven en su misma casa, a unos le van a cobrar arriendo, a otros no le van a cobrar nada. Yo nunca inscribí porque no... mi intención nunca era vender, nunca fue vender y menos si uno estaba... me estaban obligando a que yo tenía que irme, porque el día que yo quiero, yo vendo, pero no que venga alguien y me diga: "oye, ya véndeme". A mí el gobierno me ofreció mucho dinero, yo le dije: "no lo necesito, no está en venta". Nosotros nos tomamos nuestras propias casas cuando entramos también po', si esa fue la otra, y tuvimos letreros. Tenemos la foto en donde dice "esta casa está tomada por sus propios dueños", la escribimos en una bandera chilena y ahí está el letrero, esa era la toma de una casa. Eso pasó en Chaitén no más ${ }^{21}$

"el Estado no está preparado para atender una emergencia. No está preparado para atender, el retorno y la reconstrucción"22

Abril, 2012.

20 Entrevista a hombre 2, habitante de Chaitén, realizada por equipo del Centro de Investigación en Vulnerabilidades y Desastres Socionaturales (CIVDES). Abril, 2012.

21 Entrevista a mujer 1, habitante de Chaitén, realizada por equipo del Centro de Investigación en Vulnerabilidades y Desastres Socionaturales (CIVDES). Abril, 2012.

22 Entrevista a funcionaria de la Municipalidad de Chaitén, realizada por equipo del Centro de Investigación en Vulnerabilidades y Desastres Socionaturales (CIVDES). Abril, 2012. 
la verdad es que esto fue como un engaño. Todos tenían que vender las casas, incluso yo me arrepentí el último día, yo siempre pensando en que en algún momento iba a retomar, al final no vendi porque a pesar de que me había llegado una buena oferta final, la rechacé23

o fue difícil para la gente irse a otra ciudad, donde la gente va, por ejemplo, yo lo digo por la experiencia de mis suegros, ellos acostumbrados al aire libre, mi suegra a estar sembrando, cultivando, qué se yo, mi suegro ir al campo, ver sus animales y llegar a una ciudad donde una casa está llena de rejas, las ventanas, las puertas, todo con llave y no tenía nada verde. Todo pavimento. Entonces para ellos era como estar encarcelados ${ }^{24}$

"Mucha gente, un número no te puedo dar, pero un número considerable de gente, habian pasado tres años y todavía no usaban su subsidio. Mucha gente, mucha gente"25

En el año 2015, en una nueva administración del Estado, se vuelve a ratificar lo que ya entregaban las evidencias, el desencuentro profundo entre la comunidad chatenina, el desastre socionatural que los afectó de por vida y las distancias con el accionar público.

\section{DISCUSIÓN}

Los resultados y sus evidencias, demuestran que en el ejemplo de Chaitén, como referencia de un asentamiento humano afectado por el impacto de una erupción volcánica, efectivamente ha existido una comprensión reducida del fenómeno en su connotación de ser uno de tipo socionatural. La dimensión de la vivienda en él, desde una comprensión escalar, se ha escapado en su manejo y más bien fue tratada a distancia, sin contrastarla y consensuarla adecuadamente con la comunidad originaria y doblemente damnificada en cuanto a

23 Entrevista a hombre 1, habitante de Chaitén, realizada por equipo del Centro de Investigación en Vulnerabilidades y Desastres Socionaturales (CIVDES). Abril, 2012.

24 Entrevista a mujer 2, habitante de Chaitén, realizada por equipo del Centro de Investigación en Vulnerabilidades y que perdió su hábitat, fue desplazada y dispersada a múltiples localidades y a desagrado. La participación de los damnificados aparece como una variable estratégica en el diseño y gestión de las alternativas de reconstrucción, entre ellas, la relocalización de la población que quiere optar por permanecer en el lugar y su territorialidad, independientemente de la exposición a riesgos que el asentamiento posea. En ello, hay un proceso paralelo a las acciones de Estado en el tratamiento de la gestión y valoración de la vivienda, llevado, vivido y disputado por los propios chaiteninos y que sigue siendo ignorado por aquel.

Por lo expuesto en las referencias conceptuales y las entrevistas a habitantes $e$ informantes claves, algunos viviendo en Chaitén y otros fuera, se demuestra un descontento con el proceso, la existencia de una lugarización previa, destruida, resistencias y resiliencias inherentes (Cutter, Op. cit) y la apropiación del territorio poblado como parte de un hábitat, y dentro de él, la escuela- internado, lugar de cohesión colectiva y comunitaria junto a la vivienda, como un satisfactor de necesidades existenciales y axiológicas que dan sentido de pertenencia, arraigo y satisfacción.

Esas coordenadas referenciales y reconocidas no formaron parte del diseño y gestión del plan de reasentamiento del hábitat dañado, por parte del Estado, visto que las decisiones no se tomaron en conjunto con la comunidad, más todavía cuando ella, en un primer momento, se dispersó.

Hay por ello, coincidencia con otros autores cuando aquellos reportan fracasos en el tratamiento de estos fenómenos y los planes llevados a cabo para su resolución (CYTED, 2003; Gómez, op cit.; Chardón, op cit.).

¿Faltó evaluar la profundidad y características de los daños, específicamente en el satisfactor sinérgico cómo lo es la vivienda y el hábitat? ¿Faltó entender la historia de lo cotidiano y los procesos del habitar?

\section{CONCLUSIONES}

La vivienda en Chaitén, entendida ésta,

Desastres Socionaturales (CIVDES). Abril, 2012.

25 Entrevista a funcionaria de la Municipalidad de Chaitén, realizada por equipo del Centro de Investigación en Vulnerabilidades y Desastres Socionaturales (CIVDES). Abril, 2012. 
como proceso, activo de capital físico, y satisfactor sinérgico dentro de un sistema multiescalar y generador de lugares, presentó limitaciones en su tratamiento y gestión que impactan hasta la actualidad, la reconstitución de un lugar expuesto objetivamente a riesgos con vulnerabilidades, resistencias y resiliencias previas. La comunidad, en vista de la limitada gestión por parte del Estado y su institucionalidad, ha incorporado la amenaza del volcán, activo, a su lugar y la esta haciendo parte de su cotidianeidad.

El sector vivienda en Chile, en cuanto a políticas públicas desde hace más de 30 años, ha fomentado la constitución de individuos replegados al interior de las viviendas. Los entrevistados en cambio, demostraron que Chaitén como hábitat, tenía atributos que le daban un sentido de comunidad y que del cual no se sabe ya si podrá volver a reconstituir. La reconstrucción, por ello, perdió la oportunidad de potenciar el sentido mencionado al fragmentar el éxodo y el retorno al lugar fundacional.

Esta realidad, permite continuar observando el fenómeno socionatural y su desarrollo en sus múltiples dimensiones, una de ellas, el comportamiento de la vivienda como satisfactor, ubicada en una zona extrema y estratégica para Chile, con problemas de conectividad y aislamiento, en un contexto de modelo económico neoliberal.

Las evidencias de los testimonios permiten concluir que el tratamiento de la dimensión de la vivienda en la gestión en las políticas públicas aplicadas, al menos fue errática, donde no hubo un efectivo involucramiento y participación de los afectados. Un primer error, fue determinar una nueva localización y la elaboración de una nueva ciudad, desde las disciplinas de la arquitectura y el urbanismo, con un enfoque de arriba hacia abajo. No se dimensionó la magnitud y las características del impacto y el daño que el abandono y la posterior venta de las viviendas construidas por los mismos habitantes, produjo en aquellos. En aras de la eficacia de las políticas públicas hubo plazos que desconocieron la carga de significado, identidad y trauma que la población todavía mantiene. El plazo que finalmente no fue el adecuado - el reasentamiento en Santa Bárbara- y que fue posteriormente desechado por el mismo Estado -la decisión del gobierno de centro derecha- que les planteó la alternativa de volver al asentamiento original, fueron hitos negativos y controvenciales en la gestión.

Otro factor que se ha escapado de la gestión pública y donde la propia gente ha tomado su camino, en contraposición al Estado, ha sido la instalación del al menos 120 familias en el lado sur del Chaitén, a contrapelo de las decisiones del gobierno central y en acuerdo con el gobierno local.

En cuanto al rol del gobierno local, se repite el patrón histórico en la gestión de riesgos en Chile, en cuanto a que a la instancia de la administración territorial más cercana a la gente, el municipio, no se le considera un factor coadyuvante y recurso potente para asumir la reconstrucción. Se le trata como un afectado más, dándole un rol pasivo y con una relación vertical desde el Estado central hacia él, en circunstancias que en este caso queda demostrado que es una instancia, junto con el resto de la institucionalidad pública local - como por ejemplo, la escuela-internado- de ingenio y robustez, dos atributos de la resiliencia.

Hasta el 2013, la inversión que el Estado de Chile había realizado en Chaitén era de 191 millones de dólares (Diario La Tercera del 23/04/2013). Al 2014, la administración Bachelet presentó un plan de $\$ 65.743 .074 .000$ de diversas obras y proyectos para terminar de reconstruir Chaitén. (Ministerio de Interior y Seguridad Pública. Gobierno de Chile, 2014). No obstante ello, no se especifica en algunos de los documentos de los planes señalados, que se hará o como se deberá asumir un potencial o nuevo proceso de evacuación, retorno y reinstalación de la cotidianeidad, en caso de una nueva erupción, pues el volcán mantiene activo su alto nivel de peligrosidad.

La experiencia de Chaitén es un rico derrotero o laboratorio de aprendizajes para la gestión del riesgo en un país en donde las amenazas provenientes de la naturaleza, forman parte de su idiosincrasia. A la luz de lo expuesto, se requiere de más y nuevas investigaciones que puedan derivarse de esta experiencia y en donde al parecer, no hay certezas de que las decisiones tomadas hayan sido las más convenientes y acertadas. Las acciones y estrategias del Estado y las de la comunidad afectada fueron divergentes entre ellas, hasta la actualidad, como lo demuestran los resultados. 
Se estima que aún queda por obtener mucho aprendizaje de este caso en cuanto a revisar y evaluar los errores de la política pública alli producidos, versus las capacidades y aciertos de la comunidad, dentro de la ecuación de la vulnerabilidad y la resiliencia de lugar, en particular en la dimensión de la vivienda comprendida como proceso, sistema multiescalar y lugar.

Las limitaciones de la investigación se pueden identificar en la necesidad de una mayor penetración de estudios de campo en la comuna de Chaitén, con el enfoque expuesto, más allá de la ciudad del mismo nombre. Como se indicó, la comuna es más que solo el pueblo de Chaitén. Estudios que den cuenta del territorio como totalidad, más todavía cuando las divisiones administrativas a veces no coinciden con los territorios, sus particularidades, potencialidades y otras vulnerabilidades.

\section{BIBLIOGRAFÍA}

Agnew, J. A. (2005) Space: Place. En P. Cloke \& R. Johnston (Eds.) Spaces of Geographical Thought: Deconstructing Human Geography's Binaries (pp. 81-96) . London: Sage.

Arroyo, M., \& Sádaba, I. (Eds.) (2012). Metodología de la investigación social. Técnicas innovadoras y sus aplicaciones. Madrid, España. Editorial Síntesis.

Augé, M. (1993). Los no Lugares. Espacios del anonimato. Barcelona. Editorial Gedisa.

Cresswell, T. (2004) Place, a short introduction. Oxford: Blackwell.

Besoain C., \& Cornejo, M (2015). Vivienda social y subjetivación urbana en Santiago de Chile: Espacio privado, repliegue presentista y añoranza. Psicoperspectivas. Individuo y sociedad, 2(14), 16-27.

Bourdieu, P. (2001). Las Estructuras Sociales de la Economía. Editorial Manantial. Buenos Aires.

Cortés, L. (1995). La cuestión Residencial. Bases para una sociología del habitar. Madrid, España. Editorial Fundamentos.

CIAT, Centro de Investigación de Arquitectura Tradicional. Universidad Politécnica de Madrid. (2012). Declaración de Boceguillas. España.

Cutter, S., Barnes, L., Berry, M., Burton, C., Evans, E; Tate, E., \& Webb, J. (2008). A place-based model for understanding community resilience to natural disasters. Global Environmental Change. Department of Geography and Hazards \& Vulnerability Research
Institute, University of South Carolina, Columbia, SC 29223, USA, 18, 598-606.

CYTED (2003). Hábitat en Riesgo. Experiencias Latinoamericanas. Programa CYTED. SUBPROGRAMA XIV. Tecnologías de Vivienda de Interés Social. RED CYTED XIV-G Hábitat en Riesgo. Córdoba, ARGENTINA.

Chardón, A (2010). Reasentar un hábitat vulnerable. Teoría versus Praxis. Revista INVI, 70(25), 17-75.

De Soto, H. (1987). El otro sendero. Perú. Editorial El Barranco, Instituto Libertad y Desarrollo.

Diario El Mercurio (2014). Edición del 07 de mayo.

Diario La Tercera (2013). Edición del 23 de abril.

Di Virgilio, M., Guevara, T., \& Arqueros, M. (2014). Un análisis comparado sobre la implmentación de políticas de regularización de asentamientos informales en Argentina, Brasil y México. Revista INVI, 80(29), 1751.

Duran-Narucky, V. (2008). School building condition, school attendance, and academic achievement in New York City public schools: a mediation model. Journal of Environmental Psychology, 28, 278-286.

Chardón, A. (2010). Reasentar un hábitat vulnerable: teoría versus práxis. Revista INVI, 70(25), 17-75.

Falasca Mauro, Z., Christopher, W., \& Cook, D. (2008). A Decision Support Framework to Assess Supply Chain Resilience. Proceedings of the 5 th International ISCRAM Conference - Washington, DC, USA, May 2008 F. Fiedrich and B. Van de Walle, eds.

Giglia. A. (2012). El habitar y la cultura. Perspectivas teóricas y de investigación. Editorial Anthropos. Unversidad Autónoma Metropolitana, Barcelona, España.

Gilbert, A (2003). Poder, Ideología y el Consenso de Washington: Desarrollo y Expansión de la Política Chilena de Vivienda. Boletín INVI. 47(18), 133-156.

Gómez, G (2009). Procesos de Mutación Cultural desde Experiencias Cotidianas en Villa Puclaro. Revista INVI 66(24), 159-190.

González, D. (2009). La vivienda como tema de diseño. La Habana, Cuba. Editorial Félix Varela.

González, M. (2011). Estudio del Impacto Territorial Ambiental generado por la Erupción del Volcán Chaitén. (Memoria para optar al título de Geógrafo). Facultad de Arquitectura y Urbanismo, Universidad de Chile. Santiago, Chile.

Goodman, R. (1972). After the Planners. Harmondsworth: Pelican.

Haramoto, E. (1998). Vivienda-calidad (Documento). Santiago de Chile. Instituto de la Vivienda, Facultad de 
Arquitectura y Urbanismo, Universidad de Chile.

Hidalgo, R (2005). La vivienda social en Chile y la construcción del espacio urbano en el Santiago del siglo XX. Instituto de Geografía, Pontifica Universidad Católica de Chile. Centro de Investigación Diego Barros Arana. Colección Sociedad y Cultura. Santiago de Chile,

Hubb, J., \& Inbar, M. (Eds.). (2002). Desastres Naturales. México. Fondo de Cultura Económica. IPSOS Public Affairs, 2008.

Landázuri, A., \& Mercado, S (2004). Algunos factores físicos y psicológicos relacionados con la habitabilidad de la vivienda. En Medio Ambiente y Comportamiento Humano (pp. 89-113). Editorial Resma.

López, E., Arriagada, C., Jirón, P., \& Eliash, H. (Ed.). (2014) Chile Urbano hacia el siglo XXI. Política Urbana desde la Universidad de Chile. Santiago, Chile. Editorial Universitaria. Estudios.

Lhumann, N. (1998). Sociología del Riesgo. México. Editorial Triana.

Martinic, V., M. (2013) Apertura del Istmo de Ofqui: Estudio de una quimera. Consideraciones sobre la vigencia de sus razones. Magallania, 2(41), 5-50.

Max Neef, M., Elizalde, A., \& Hopenhayn, M. (1986). Desarrollo a Escala Humana. Una opción para el futuro. Santiago, Chile. CEPAUR, Fundación Hammarskjöld.

Merton, R. K., West, P., Jahoda, M., \& Selvin, S. (1963). Sociología de la Vivienda. Buenos Aires. Editorial PAIDÓS.

Ministerio de Interior y Seguridad Pública. Gobierno de Chile (2014). Plan de Reconstrucción Chaitén. Delegación Presidencial para la Reconstrucción. Editorial ANDROS. Santiago, Chile.

Ministerio de Vivienda y Urbanismo (2013). Vol.1. Hacia una nueva política urbana para Chile. Antecedentes históricos. Santiago, Chile.

Ministerio de Vivienda y Urbanismo (2013). Vol.4. Hacia una nueva politica urbana para Chile. Política Nacional de Desarrollo Urbano. Santiago, Chile.

Moreira, R. (2006). Playa Guanímar. Reubicación y Reconstrucción de la vivienda: una estrategia en un hábitat en riesgo. Revista de Ordenamiento Territorial y Urbanismo, 10, 20-27.

Moser, C., \& Felton, A. (2009). Acumulación intergeneracional de activos y reducción de la pobreza en Guayaquil, Ecuador entre 1979 y 2004. En Moser C. (Ed.). Reducing Global Poverty: The Case for Asset Accumulation (pp. 15-50). Washington DC: Brookings Press.
Muntañola, J (1973). La arquitectura como Lugar. Aspectos preliminares de una Espistemología de la Arquitectura. Barcelona. Editorial Gustavo Gili.

Norberg-Schultz, CH. (1983). Arquitectura Occidental. Barcelona. Editorial Gustavo Gili.

Ortíz, E. (1998). Notas sobre la producción social de la vivienda, elementos básicos para su Conceptualización e impulso. México D.F., Casa y Ciudad, Ciudad de México.

Olavarría, M. (2007). Conceptos Básicos en el Análisis de las políticas públicas. (Documento de Trabajo $\mathrm{N}^{\circ}$ 11-diciembre-2007). Santiago, Chile. Instituto de Asuntos Públicos. Departamento de Gestión Pública. Universidad de Chile.

ONEMI (2010). Actividad volcánica de Chile año 2008. Unidad de Gestión Territorial, División de Protección Civil.

Kellett, P. (2002). The construction of home in the informal city', Journal of Romance Studies, 2(3), 17-31.

Pontificia Universidad Católica de Chile, Universidad Austral de Chile (2008). Observatorio de Ciudades Universidad Católica. Consultoría para el Desarrollo de Lineamientos Estratégicos de Reconstrucción y Plan Maestro Conceptual Post-Desastre Chaitén. Santiago, Chile.

Programa CYTED. Subprograma XIV. Tecnologías de Vivienda de Interés Social. RED XIV-G Hábitat en Riesgo. (2003). Hábitat en Riesgo. Experiencias Latinoamericanas. Córdoba. Argentina.

Proshansky, H. M., Ittelson, W. H., \& Rivlin, L. G. (1983). (Eds.). Psicología Ambiental: El hombre y su entorno físico. México. Editorial Trillas.

Sáez, E., García, J., \& Roch, F. (2010). La ciudad desde la casa: Ciudades espontáneas en Lima. Revista INVI, 70(25), 77-116.

Salazar, G. (2009). Bicentenario en Chile: ¿Qué pueblo para qué ciudad? Revista INVI, 57(24) 9-18.

Sepúlveda, R., De la Puente, P., Torres, E., \& Tapia, R. (1999). Seguridad Residencial y Comunidad. Universidad de Chile. Facultad de Arquitectura y Urbanismo, Instituto de la Vivienda. Facultad de Ciencias Sociales. Departamento de Sociología, Santiago, Chile

SIMMEL, G. (1939). Sociología. Buenos Aires. Editorial Espasa-Calpe.

Raposo, A. (1998). La racionalidad tecno-instrumental en el accionar político-administrativo del Estado. Elementos para un modelo descriptivo. Boletín INVI 35(13), 116138.

Rapoport, A. (1972). Vivienda y Cultura. Editorial Gustavo 
Gili, Barcelona.

RED XIV.F Tecnologías Sociales y Producción Social del Hábitat (2007). Herramientas de Planeamiento Participativo para la Gestión Local y el Hábitat. Oliveras, R; Mesías, R; Romero, G (Eds.). La Habana, Cuba. Subprograma XIV-Tecnologías para Viviendas de Interés Social. HABYTED, del Programa Iberoamericano de Ciencia y Tecnología para el Desarrollo, CYTED.

Tapia, R. (2012). Chaitén, Chile: Aprendizajes de un proceso de expulsión, reasentamiento y retorno humano en desarrollo como consecuencia de la erupción volcánica y aluvión del Volcán Chaitén en el año 2008. En Actas del Congreso del XIII Coloquio Ibérico de Geografía, octubre, 2012 (pp. 990-999), Universidad de Santiago de Compostela, España.

Tiburcio, P. (2008). Arquitectura vernácula y diseño: adecuación del espacio habitable en la ciudad de Nogales, Sonora. (Tesis que para obtener el grado de Maestro en Ciencias Sociales). El Colegio de Sonora, Sonora, México.

Tuan, Y, F (1974). Topophilia: A study of environmental perception, attitudes and values. New York, NY. Columbia University Press.

Turner, J. (1972). Housing as a Verb. En J. Turner \& R. Fichter (Eds.) Freedom to Build: Dweller control of the housing process (pp. 148-75), New York: CollierMacmillan. 